\title{
In vitro, acute and subchronic evaluation of the antidiabetic activity of Atractylis flava Desf $n$-butanol extract in alloxan-diabetic rats
}

\author{
Mohamed Akram Melakhessou ${ }^{1 *}$ (D), Salah Eddine Marref ${ }^{1}$, Naima Benkiki ${ }^{1}$, Cherine Marref ${ }^{2}$, \\ Imene Becheker ${ }^{3}$ and Latifa Khattabi ${ }^{4}$
}

\begin{abstract}
Background: Diabetes mellitus is a serious complex multifactorial disorder that imposes huge health and economic burden on societies. Because the currently available medications have many drawbacks, it's important to look for alternative therapies. Medicinal plants utilized in folk medicine are ideal candidates. Therefore, this work assessed the antidiabetic action of $n$-butanol extract from the whole plant Atractylis flava Desf (BEAF). These ethnomedicinal properties of BEAF were scientifically validated using in vitro and in vivo assays. In vitro antidiabetic effect of the BEAF was conducted using a-Glucosidase and a-Amylase assays. While the antihyperglycemic activity was assessed using two rat models: Alloxan-induced diabetic rats and oral glucose challenged rats. Experimental diabetes was induced by a single intraperitoneal injection of alloxan at a dose of $150 \mathrm{mg} / \mathrm{kg}$ and animals with fasting blood glucose levels $(\mathrm{BGL})>200 \mathrm{mg} / \mathrm{dL}$ were considered diabetic. Glibenclamide $(5 \mathrm{mg} / \mathrm{kg}$ ) was used as a typical drug.
\end{abstract}

Results: The BEAF at all tested dose levels $(100,250$, and $500 \mathrm{mg} / \mathrm{kg}$ ) showed a significant decrease in blood glucose level in all the two animal models. Besides, the plant extract exhibited a potent inhibitory effect on a-Amylase and a-Glucosidase activity at a concentration of $1000 \mu \mathrm{g} / \mathrm{mL}$ with $76.17 \%$ and $89.37 \%$, respectively.

Conclusion: BEAF exerts in vitro and in vivo antidiabetic effects, these results suggest that the plant extract can be a therapeutic resource in the treatment of diabetes and hyperlipidemia.

Keywords: Atractylis flava Desf, Alloxan, a-Amylase, a-Glucosidase, Diabetes mellitus

\section{Background}

Diabetes is a chronic disease associated with elevated blood glucose levels, triggered by the combination of hereditary and environmental sources which cause an abnormally high blood sugar level [1]. It is a major health issue in both developed and undeveloped countries [2]. Even though many therapies are available for the treatment of diabetes, they do not cure the disease completely and cause various complications. Many natural products

\footnotetext{
*Correspondence: Akram_med@hotmail.fr; m.melakhessou@univ-batna2.dz ${ }^{1}$ Laboratoire de Biotechnologie des Molécules Bioactives et de la Physiopathologie Cellulaire (LBMBPC), Université de Batna-2, 05000 Batna, Algeria

Full list of author information is available at the end of the article
}

with hypoglycemic effects have been appraised and confirmed for their antidiabetic activities in animal models which propose that the world is searching for new antidiabetic agents from plant sources with fewer undesirable effects [3]. Inhibition of carbohydrate-hydrolyzing enzymes, such as $\alpha$-Amylase, and $\alpha$-Glucosidase is one of the most notable therapeutic approaches to decrease the high blood sugar level, by hindering the uptake of glucose [4]. However, natural plant substances that block $\alpha$-Glucosidase and $\alpha$-Amylase activities offer an attractive strategy for the control of postprandial hyperglycemia in type 2 diabetic patients.

Atractylis flava Desf. (Asteraceae), locally called assenan aouragh in Algeria is one of the traditional 
medicinal plants which are widely distributed in the Mediterranean zone [5]. A.flava has shown significant antioxidant, anticancer, anti-inflammatory, and antipyretic activities [6-8]. Nonetheless, many health issues such as circulatory disorders, ulcers, intestinal parasites, and snakebite poisoning have been treated by a folk herbal drug made from Atractylis plants, while A. flava has also been reported to possess diuretic effects $[9,10]$. Different classes of phytochemical constituents have been isolated from the whole plant A. flava, e.g., triterpenes, steroids, saponins, and flavonoids. Furthermore, the presence of narcissin, tiliroside, ladaneine, and vicenin 3 was confirmed in the $n$-butanol extract [11]. Among these phytochemical constituents, tiliroside and vicenin3 have been shown to exhibit antidiabetic activity $[12,13]$. Before the present study, there is no statement on the antidiabetic activity of $A$. flava. Therefore, this study was to investigate whether the $n$-butanol extract of the whole plant $A$. flava possessed antidiabetic activity or not.

\section{Methods}

\section{Plant authentication}

The whole plant $A$. flava was collected from the Biskra District in southern Algeria. The plant was identified by its vernacular name and later confirmed at Agronomic Institute, University of Banta, by Professor Bachir Oudjehih and Voucher specimen with the corresponding number (660/LCCE) was deposited at the Griffin Herbarium of the mentioned Institute.

\section{Preparation of extracts}

Dried and powdered plant material (1000 g) was macerated with the solvent mixture methanol/water 80:20 (v/v). The recovered quantity was filtrated and concentrated under vacuum at ambient temperature. The hydroalcoholic extract was submitted to liquid-liquid fractioning using (petroleum ether, dichloromethane, ethyl acetate, and $n$-butanol). The $n$-butanol fraction was used to evaluate the $\alpha$-Glucosidase and $\alpha$-Amylase inhibitory and the antihyperglycemic activity.

\section{Experimental animals}

Only male Wistar albino rats weighted from 150 to $180 \mathrm{~g}$, aged 2-3 months were handled to evaluate the antidiabetic activity. Rats were obtained from the Pasteur Institute, Algiers, Algeria, and were fed a standard laboratory diet and allowed water ad libitum. This study was approved by the ethics committee of Pasteur Institute, Algiers, Algeria, ethics with approval voucher number VB09268.

\section{In vitro antidiabetic activities a-Amylase inhibitory activity}

The $\alpha$-Amylase inhibition assay was determined by using the dinitrosalicylic acid (DNS) method [14]. Different concentrations $(62.5-1000 \mu \mathrm{g} / \mathrm{mL})$ of BEAF were prepared from a $1 \mathrm{mg} / \mathrm{mL}$ stock solution of phosphate buffer. The samples $(100 \mu \mathrm{L})$ were incubated with $100 \mu \mathrm{L}$ of $\alpha$-Amylase solution $(0.02 \mathrm{~mol} / \mathrm{L}$ for $30 \mathrm{~min}$ at room temperature. Then $100 \mu \mathrm{L}$ of starch solution (1\%) was added and incubated for another $10 \mathrm{~min}$. The mixture was heated $5 \mathrm{~min}$ in a boiling water bath after adding $1 \mathrm{~mL}$ of DNS color reagent that stops the reaction. Then it was allowed to cool and was diluted by adding distilled water $(5 \mathrm{~mL})$. The blank was prepared by replacing the enzyme with a buffer for each set of concentrations of the test sample. The control was maintained without the addition of a sample that represented $100 \%$ enzyme activity. The absorbance of the color solution was measured at $540 \mathrm{~nm}$ using ultraviolet-visible spectrophotometer (Jenway ${ }^{\mathrm{TM}}$ 6305). Acarbose serves the experiment as a positive control.

\section{a-Glucosidase inhibitory activity}

The $\alpha$-Glucosidase inhibitory activity of the BEAF was tested by measuring the 4-nitrophenol released from $\rho$-nitrophenyl $\alpha-D$ glucopyranoside $(\rho N P G)$. The different concentrations $(62.5-1000 \mu \mathrm{g} / \mathrm{mL})$ of a sample $(200$ $\mu \mathrm{L}$ ) were added to the assay mixtures containing $700 \mu \mathrm{L}$ of $10 \mathrm{mM} \rho$-nitrophenyl $\alpha$-D glucopyranoside, $1.0 \mathrm{~mL}$ of potassium phosphate $(0.1 \mathrm{M}, \mathrm{pH}: 6.8), 200 \mu \mathrm{L}$ of enzyme solution and incubated for $6 \mathrm{~min}$ at $37 \mathrm{C}$. The addition of $100 \mathrm{mM}$ sodium carbonate $(1 \mathrm{~mL})$ terminated the reaction. The liberated $\rho$-nitrophenol was estimated by determining the absorbance at $405 \mathrm{~nm}$ using a spectrophotometer (Jenway ${ }^{\mathrm{TM}}$ 6305). A positive control (Acarbose) was used to compare the inhibitory activity of BEAF. The percentage of inhibition was calculated to express the $\alpha$-Glucosidase inhibitory activity [15].

\section{In vivo antidiabetic activities \\ Oral Glucose Tolerance Test (OGTT) in rats}

Rats were fasted for $12 \mathrm{~h}$, except for water ad libitum, and haphazardly divided into three groups $(n=5)$. Group I (normal control) rats were treated with vehicle $(\mathrm{NaCl} 0.9 \%)$; groups II, III were treated with $250 \mathrm{mg} / \mathrm{kg}$ and $500 \mathrm{mg} / \mathrm{kg} n$-butanol extract, respectively. Animals were orally administered in a unique dose, the $n$-butanol extract that was dissolved in $0.9 \% \mathrm{NaCl}$. Thirty minutes after treatment all the animals received $4 \mathrm{~g} / \mathrm{kg}$ of glucose solution. Blood was collected from the tail tip of each rat and BGL was measured immediately before treatment 
using an Accu-chek Active ${ }^{\mathrm{TM}}$ test glucometer at 0 (as a baseline), 60, 90, and $120 \mathrm{~min}$ and of glucose administration [16].

\section{Induction of experimental diabetes}

A dose of $125 \mathrm{mg} / \mathrm{kg}$ of freshly prepared alloxan (SigmaAldrich (St. Louis, MO) $(0.9 \% \mathrm{NaCl})$ was sufficient to induce diabetes by a single intraperitoneal injection of overnight fasted male rats [17]. Animals were given free access to water and pellet diet after $30 \mathrm{~min}$ of alloxan administration. Animals were kept under rigorous surveillance, the fasting BGL was recorded after seven days alloxan injection using a glucometer. The selection of rats that will be included in the study was based on the criteria of having a fasting BGL greater than $200 \mathrm{mg} / \mathrm{dL}$ [18].

\section{Acute and subchronic antidiabetic activity in alloxan-induced diabetes model}

The chosen diabetic animals were scattered into 5 groups $(\mathrm{n}=5)$. Group 1 was defined as a negative control, received a single dose of $1 \mathrm{~mL} / 100 \mathrm{~g}$ of the vehicle, group 2 was considered as positive control, treated with glibenclamide $(5 \mathrm{mg} / \mathrm{kg})$ as a reference drug. Groups 3 to 5 were treated with BEAF at three dose levels $(100,250$ and $500 \mathrm{mg} / \mathrm{kg}$ ). Blood was collected from the tail tip of each mouse and BGL was measured immediately before treatment at 0 (as a baseline), 30, 60, 90, and $120 \mathrm{~min}$ of BEAF administration. Treatment was extended for 7 consecutive days (p.o.). At the end of day 7 , the rats have fasted for $16 \mathrm{~h}$ and blood parameters were determined, the rats were thereafter sacrificed by cervical dislocation and the blood samples were collected through cardiac puncture from the posterior vena cava.

\section{Estimation of biochemical parameters}

The BGL was measured using an Accu-chek Active ${ }^{\mathrm{TM}}$ test glucometer by collecting the blood from the rat tail vein. For other plasma parameters, at the end of treatment, i.e., 7 days, blood was collected from rats retro-orbital plexus applying a light ether anesthesia method. The plasma was restricted by centrifuging at $3000 \mathrm{rpm}$ for $5 \mathrm{~min}$ and was checked out for lipid profiles (total cholesterol (TC), triglyceride (TG), high-density lipoprotein (HDL), lowdensity lipoprotein (LDL)), creatinine, and urea that were analyzed by standard enzymatic assays with an automatic analyzer (COBAS INTEGRA ${ }^{\circledR} 400$ plus).

\section{Statistical analysis}

All the data were expressed as mean \pm SEM, and oneway analysis of variance (ANOVA) followed by Dunnett's test was used for statistical analysis by using GraphPad Prism software (version 7.0). Significance was assumed if $P<0.05$.

\section{Results}

In vitro antidiabetic activity

a-Amylase and a-glucosidase inhibitory

As illustrated in Fig. 1, the BEAF showed a significant $(P<0.05) \quad \alpha$-Amylase inhibitory activity in a concentration dependent manner. The BEAF at a concentration of $1000 \mu \mathrm{g} / \mathrm{mL}$ exhibited $76.17 \%$. Moreover, the $\alpha$-Glucosidase inhibitory effect of the extract was more efficient than $\alpha$-Amylase inhibition with $89.37 \%$ at $1000 \mu \mathrm{g} / \mathrm{mL}$. Similarly, acarbose, at $1000 \mu \mathrm{g} / \mathrm{ml}$ showed roughly $100 \%$ enzyme inhibition.

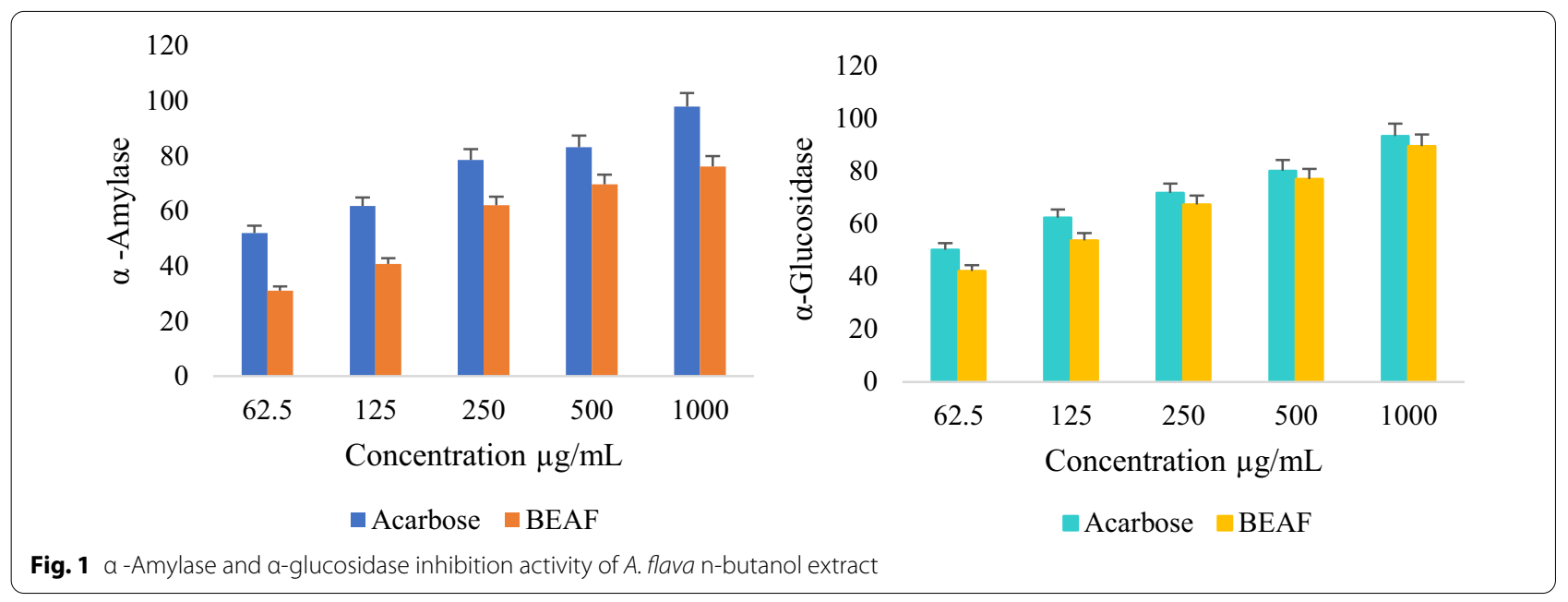




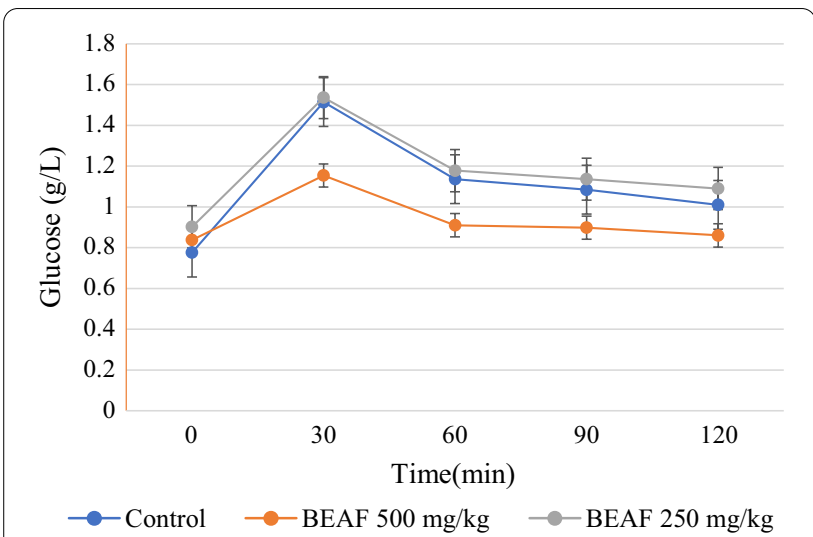

Fig. 2 Effect of BEAF on oral glucose tolerance test (OGTT) in rats

\section{In vivo antidiabetic activity}

\section{Oral Glucose Tolerance Test (OGTT) in rats}

As indicated in Fig. 2, there were no significant differences in blood glucose level among all the groups $(P>0.05)$ before glucose administration. But, all groups showed significant increase in BGL 30 min following glucose loading, confirming the induction of hyperglycemia.
The hyperglycemia was significantly decreased by the BEAF at a dose of $500 \mathrm{mg} / \mathrm{kg}(P<0.01)$, after $60 \mathrm{~min}$ of administration relative to normal control.

\section{Acute and subchronic antidiabetic activity in alloxan-induced diabetes model}

As shown in Table 1, the BEAF and the standard drug demonstrated a significant blood glucose-lowering effect in all diabetic-treated groups in a concentration-dependent manner as compared to the diabetic control. The BEAF at $500 \mathrm{mg} / \mathrm{kg}$ significantly $(P<0.01)$ lowered the fasting BGL with $56.20 \%$. After 7 days, values of blood glucose decreased in all the treatment groups and the diabetic control rats showed a notable increase in blood glucose level. The administration of BEAF at $500 \mathrm{mg} / \mathrm{kg}$ and glibenclamide to diabetic rats restored the BGL significantly $(P<0.01)$ (Table 1$)$.

The level of urea, creatinine, and lipid profiles of different experimental groups are also represented in Table 2. Therefore, the diabetic rats showed significant hypertriglyceridemia and hypercholesterolemia as compared with control. Treatment with BEAF showed a significant decrease in cholesterol and triglycerides levels simultaneously increased the HDL-cholesterol. Concerning the

Table 1 Effects of BEAF on blood glucose level on alloxan-induced diabetic rats

\begin{tabular}{|c|c|c|c|c|}
\hline \multirow[b]{2}{*}{ Time } & \multicolumn{4}{|c|}{ Blood glucose inhibition (\%) } \\
\hline & $30 \mathrm{~min}$ & $60 \mathrm{~min}$ & $90 \mathrm{~min}$ & $120 \mathrm{~min}$ \\
\hline $0.9 \% \mathrm{NaCl}$ & $1.72 \pm 0.29$ & $2.57 \pm 0.38$ & $-0.18 \pm 0.38$ & $-2.69 \pm 0.44$ \\
\hline Glibenclamide & $35.04 \pm 0.45^{* * *}$ & $39.33 \pm 1.01^{* * *}$ & $45.08 \pm 0.95^{* * *}$ & $56.20 \pm 0.71^{* * *}$ \\
\hline BEAF 500 mg/kg & $16.80 \pm 0.48^{* * *}$ & $23.90 \pm 0.63^{* * *}$ & $29.49 \pm 0.54^{* * *}$ & $39.40 \pm 0.69^{* * *}$ \\
\hline BEAF $250 \mathrm{mg} / \mathrm{kg}$ & $9.48 \pm 0.29 * * *$ & $17.60 \pm 0.70^{* * *}$ & $28.59 \pm 0.68^{* * *}$ & $29.18 \pm 0.83^{* * *}$ \\
\hline BEAF $100 \mathrm{mg} / \mathrm{kg}$ & $3.94 \pm 0.70^{*}$ & $8.82 \pm 0.96^{* * *}$ & $16.08 \pm 0.88^{* * *}$ & $18.81 \pm 1.69^{* * *}$ \\
\hline
\end{tabular}

Each value represents the mean $\pm \mathrm{SEM} n=5$. ${ }^{*} P<0.05 ;{ }^{* * *} P<0.001$ versus normal control (ANOVA followed by Dunnett's test)

Table 2 Biochemical parameters of normal and diabetic animals on 7th day post-treatment

\begin{tabular}{lccc}
\hline Parameters & Normal control & Diabetic control & BEAF (500 mg/kg) \\
\hline Liver profile & & & Glibenclamide (5 mg/kg) \\
ASAT(U/L) & $141 \pm 4.23$ & $143.2 \pm 6.77$ & $187.6 \pm 5.98$ \\
ALAT(U/L) & $78.3 \pm 6.12$ & $80.8 \pm 8.76$ & $98.5 \pm 8.86$ \\
Renal profile & & & $172.4 \pm 9.66 * *$ \\
Urea (mg/L) & $0.28 \pm 0.01$ & $0.77 \pm 0.51^{*}$ & $0.32 \pm 0.01$ \\
Creatinine (mg/L) & $3.45 \pm 1.71$ & $6.30 \pm 0.16^{* *}$ & $3.78 \pm 0.20$ \\
Lipid profile & & & $0.32 \pm 0.01$ \\
Cholesterol (mmol/L) & $0.97 \pm 1.10$ & $02.03 \pm 0.05^{* *}$ & $3 \pm 0.08$ \\
Triglycerides (mmol/L) & $0.62 \pm 0.05$ & $2.14 \pm 0.15^{* *}$ & $1.14 \pm 0.15$ \\
HDL-cholesterol (mmol/L) & $0.60 \pm 0.06$ & $0.24 \pm 0.06^{* *}$ & $0.54 \pm 0.06$ \\
LDL-cholesterol (mmol/L) & $0.10 \pm 0.11$ & $0.66 \pm 0.01^{* *}$ & $1.08 \pm 0.05$ \\
Blood glucose (g/L) & $0.87 \pm 0.13$ & $3.68 \pm 0.05^{* *}$ & $0.26 \pm 0.01$ \\
\hline
\end{tabular}


ALAT and ASAT levels, the results showed that the normal control and the diabetic rats treated with the BEAF were nearly the same. However, glibenclamide-treated rats had a higher level than these two groups. The ASAT level of the diabetic rats was the highest among the groups with a value of $343.2 \mathrm{UI} / \mathrm{L}$.

\section{Discussion}

Uses of medicinal plants for the treatment of various diseases have their own merits and demerits. Diabetes mellitus is one of the major public health problems worldwide, is a metabolic disorder that bears a lot of complications if it is not properly managed. Managing diabetes with medicines is quiet costly and the chances of side effects are high. Different extracts from medicinal plants offer a promising alternative for the development of new therapeutic agents against diabetes mellitus. This study sketches out the antidiabetic activities of $A$. flava $n$-butanol extract using $\alpha$-Amylase, $\alpha$-Glucosidase inhibition activity, and alloxan-induced diabetic model.

$\alpha$-Amylase and $\alpha$-Glucosidase are the main enzymes involved in the breakdown of sugars in the human body and leads to a raised level of postprandial hyperglycemia (PPHG) SPS:refid::bib19[19]. Pancreatic $\alpha$-Amylase is responsible for the breakdown of starch into oligosaccharides which are further broken down by $\alpha$-Glucosidase into glucose. The resulting glucose enters the bloodstream upon absorption and leads to a raised level of postprandial hyperglycemia [19]. Inhibitors of these enzymes contribute to lowering postprandial hyperglycemia and slowing carbohydrate absorption in type 2 diabetic patients [20]. Therefore, plant that has the potential to inhibit the aforementioned two enzymes may be valuable in lowering postprandial hyperglycemia. In the present study, the $n$-butanol extract inhibited $\alpha$-Glucosidase and $\alpha$-Amylase efficiently and the results were comparable with acarbose a standard inhibitor of these enzymes that inhibited both of them with $76.17 \% \mu \mathrm{g} / \mathrm{mL}$ and $89.37 \%$, respectively.

Similarly, oral administration of $A$. flava $n$-butanol extract at all tested doses $(100,250$ and $500 \mathrm{mg} / \mathrm{kg})$ and glibenclamide at a dose of $5 \mathrm{mg} / \mathrm{kg}$ produced a significant reduction in BGL of normoglycemic rats. Besides, oral administration of $A$. flava $n$-butanol extract at a dose of $500 \mathrm{mg} / \mathrm{kg}$ to glucose loaded rates showed a significant reduction in BGL at 60 - and 120 -min post-treatment compared to untreated groups. This signifies that the BEAF may improve glucose tolerance in normal rats, reflecting its potential benefit to lower PPHG.

One of the strategies for the management of type 2 diabetes and OGTT is the measure of the body's ability to utilize glucose that serves as standard procedure for the diagnosis of the border line of diabetic patients in a clinical set-up [21]. The observed effect may partly flow from to attenuation of glucose absorption into bloodstreams via inhibition of $\alpha$-Amylase as this extract has demonstrated $\alpha$-Amylase inhibitory activity. Moreover, the power to enhance glucose tolerance could be thanks to other possible mechanisms just like the stimulation of glycogenesis within the liver, enhanced tissue glucose utilization, and decreased gluconeogenesis [22].

Alloxan provokes the increase of glycemia by a selective cytotoxic effect on pancreatic $\beta$-cells. One of the intracellular phenomena for its cytotoxicity is through the generation of free radicals demonstrated both in vivo and in vitro [23]. Administration of BEAF and glibenclamide resulted in a blood glucose-lowering effect compared with diabetic control rats. This result suggests that the action of BEAF may be mediated by stimulation of insulin release from the remaining pancreatic $\beta$-cells in diabetic rats.

Metabolic wastes, such as creatinine and urea, are removed by the kidney; however, in persistent hyperglycemia, increased levels of urea and creatinine are observed, which may be due to renal damage caused by diabetes [24]. In the present study, the elevation of plasma levels of urea and creatinine were observed in diabetic rats, but BEAF treatment significantly reduced serum urea and creatinine levels. This is possibly due to BEAF mediated reductions in blood glucose, which prevented hyperglycemia-associated kidney damage in diabetic rats. This action supports a protective effect of BEAF on the kidneys.

The provenance of type 2 diabetes-associated cardiovascular troubles is by virtue of lowered HDL and elevated TG and LDL levels [25]. Atherosclerotic plaque formation is aggravated by the accumulation of serum lipids in the arterial wall, and the risk of coronary heart disease increased in diabetic patients [26, 27] Antidiabetic drugs have been reported to reduce the cardiovascular risk by controlling the lipid profile level in diabetic patients [28, 29]. In our study, hypertriglyceridemia, hypercholesterolemia, and decreases in HDL were observed in untreated diabetic rats, which confirms altered lipid metabolism. Treatment with BEAF and glibenclamide reduced TC and TG and increased HDL levels compared with diabetic control rats. This finding supports the potential of BEAF to prevent the atherogenic formation in diabetes by normalizing the lipid profile and thus possibly reducing diabetic cardiovascular risk.

Our previously reported data on $A$. flava verifies its anti-inflammatory, antipyretic, antioxidant, and anticancer potentials [6-8]. Some of the compounds present in the $n$-butanol extract of $A$. flava have already been confirmed to possess antidiabetic activities, for instance, the tiliroside and vicenin 3 [11]. Although several chemical 
compounds are present in the $n$-butanol of A. flava, the most active compounds responsible for the observed antidiabetic effect were nominated based on reported studies in the literature [12, 13]. Accordingly, these results encourage further studies on extracts and identify particular active chemical compounds responsible for the specific biological activity to standardize the plant preparation for maximum therapeutic benefit to treat type 2 diabetes.

\section{Conclusion}

The BEAF has the potential to reduce blood glucose alloxan-induced diabetic rats, stimulates and inhibits $\alpha$-Glucosidase and $\alpha$-Amylase enzymes. We proclaim that is possibly by the reason of abundant active polyphenolic constituents. The results of the present study provide valid scientific evidence for therapeutic potential of A. flava in the treatment of T2D. That is why it would be interesting to fractionate the $n$-butanol ethanol root extract of $A$. flava, to determine the chemical structures of the active compounds and consequently understand the action mechanism involved in the antidiabetic effect of this medicinal plant. As a continuity to the current research investigation, the authors urge and insist on the importance of this eminent area of plant studying in the future.

\section{Abbreviations}

BEAF: $n$-Butanol extract of Atractylis flava Desf; MetOH: Methanol; OGTT: Oral glucose tolerance test; BGL: Fasting blood glucose levels; TC: Total cholesterol; TG: Triglyceride; HDL: High-density lipoprotein; LDL: Low-density lipoprotein.

\section{Acknowledgements}

Not applicable.

\section{Authors' contributions}

M.A.M: writing the original draft, conceptualized, designed the experiments, and edited the article text. S.E.M: performed the animal experiments and edited the article text. N.B: supervision. C.M and I.B: participated in the experimental and data analysis. L.K: checked the paper content and helped in data analysis. All authors read and approved the final manuscript.

\section{Funding}

Not applicable.

\section{Availability of data and materials}

All data and materials are available upon request.

\section{Declarations}

Ethics approval and consent to participate

This study was approved by the ethics committee of Pasteur Institute, Algiers, Algeria, ethics with approval voucher number VB09268. The rats were fed with Pelletized grower poultry feeds and water was provided ad libitum. All experimental protocols were carried out according to internationally approved principles for the handling of experimental animal, use and care.

\section{Consent for publication}

Not applicable.

\section{Competing interests}

The authors declare that they have no competing interests.

\section{Author details}

${ }^{1}$ Laboratoire de Biotechnologie des Molécules Bioactives et de la Physiopathologie Cellulaire (LBMBPC), Université de Batna-2, 05000 Batna, Algeria. ${ }^{2}$ Laboratoire Biologie, Eau et Environnement (LBEE), Faculté SNTV-STU, Université 8 Mai 1945 Guelma, BP 401, 24000 Guelma, Algeria. ${ }^{3}$ Laboratoire de recherche Interactions, Biodiversité, Écosystèmes et Biotechnologie (LRIBEB), 21000 Skikda, Algeria. ${ }^{4}$ Centre de Recherche en Biotechnologie (CRBt), 25000 Constantine, Algeria.

Received: 3 April 2021 Accepted: 6 October 2021

Published online: 16 October 2021

\section{References}

1. Wu YL, Ding YP, Gao J, Tanaka Y, Zhang W (2013) Risk factors and primary prevention trials for type 1 diabetes. Int J Biol Sci 9(7):666-679

2. Hu FB (2011) Globalization of diabetes: the role of diet, lifestyle, and genes. Diabetes Care 34(6):1249-1257

3. Khan V, Najmi AK, Akhtar M, Aqil M, Mujeeb M, Pillai KK (2012) A pharmacological appraisal of medicinal plants with antidiabetic potential. J Pharm Bioallied Sci 4:27-42

4. Baldea LAN, Martineau LC, Benhaddou-Andaloussi A, Arnason JT, Levy E, Haddad PS (2012) Inhibition of intestinal glucose absorption by antidiabetic medicinal plants derived from the James Bay Cree traditional pharmacopeia. J Ethnopharmacol 132(2):473-482

5. Quezel P, Santa S (1963) Nouvelle flore de l'Algérie et des régions désertiques méridionales. CNRS, Paris, France (1-2)

6. Akram MM, Naima B, Eddine MS, Soumia B (2018) Anti-Inflammatory, antipyretic and acute toxicity effects of n-butanol extract of Atractylis Flava desf in rats. Pharmacog J 10(4):763-767

7. Akram MM, Naima B, Eddine MS, Joubert O, Doumandji ZM, Safar R (2019) Gene expression levels of selected factors in monocytic leukemia cell line THP-1 upon treatment with n-butanol extract of Atractylis flava Desf against Cancer J Young Pharm. 11(1):36-9.

8. Melakhessou MA, Benkiki N, Marref SE (2018) Determination of antioxidant capacity, flavonoids and total phenolic content of extracts from Atractylis flava Desf. Res J Pharm Tech 11(12):5221-5226. https://doi.org/ 10.5958/0974-360X.2018.00952.6

9. Daniele C, Dahamna S, Firuzi O, Sekfali N, Saso L, Mazzanti G (2005) Atractylis gummifera L Poisoning: an ethnopharmacological review. J Ethnopharmacol 97(2):175-181

10. El Rhaffari L, Zaid A (2002) Pratique de la phytothérapie dans le sud-est du Maroc (Tafilalet). Un savoir empirique pour une pharmacopée rénoveé. Dans J. Fleurentin (éd.), Des sources du savoir auxmédicaments du futur, IRD editions, Paris. 293-318

11. Chabani S, Haba H, Lavaud C, Benkhaled M, Harakat D (2013) Flavonoid glycosides and triterpenoids from Atractylis flava. Phytochem Lett 6(1):9-13

12. Islam MN, Ishita IJ, Jung HA (2014) Choi I S (2014) Vicenin 2 isolated from Artemisia capillaris exhibited potent anti-glycation properties. Food Chem Toxicol 69:55-62

13. Goto T, Horita M, Nagai H, Nagatomo A, Nishida N, Matsuura Y, Nagaoka S (2012) Tiliroside a glycosidic flavonoid, inhibits carbohydrate digestion and glucose absorption in the gastrointestinal tract. Mol Nutr Food Res 56(3):435-445

14. Mccue P, Shetty K (2004) Inhibitory effects of rosmarinic acid extracts on porcine pancreatic amylase in vitro. Asian Pac J Clin Nutr 2004(13):101-106

15. Kim YM, Jeong YK, Wang MH, Lee WY, Rhee HI (2005) Inhibitory effects of pine bark extract on alpha glucosidase activity and postprandial hyperglycemia. Nutrition 21:756-761

16. Babu V, Ganga DT, Subramonium A (2002) Antihyperglycaemic activity of Cassia kleinii leaf extract in glucose fed normal ratsand alloxan induced diabetic rats. Indian J Pharmacol 34:409-413

17. Diatewa M, Badila Samba C, Hondi Assah TC, Abena AA (2004) Hypoglycemic and antihyperglycemiceffects of diethyl ether fraction isolated 
from the aqueous extract of the leaves of Cogniauxia podoleana Baillon in normal and alloxan-induced diabetic rats. J Ethnopharmacol 92:229-232

18. Usman UZ, Bakar ABA, Mohamed M (2018) Propolis improves pregnancy outcomes and placental oxidative stress status in streptozotocin-induced diabetic rats. BMC Complement Altern Med 18:324. https://doi.org/10. 1186/s12906-018-2391-6

19. Nair SS, Kavrekar V, Mishra A (2013) In vitro studies on alpha amylase and alpha glucosidase inhibitory activities of selected plant extracts. Eur J Exp Biol 3:128-132

20. Figueiredo-González M, Reboredo-Rodríguez P, González-Barreiro C, Simal-Gándara J, Valentão P, Carrasco-Pancorbo A, Andrade PB, CanchoGrande B (2018) Evaluation of the neuroprotective and antidiabetic potential of phenol-rich extracts from virgin olive oils by in vitro assays. Food Res Int 106:558-567

21. Etuk EU (2010) (2010) Animals models for studying diabetes mellitus. Agric Biol J N Am 1(2):130-134

22. Tesfaye A, Makonnen E, Gedamu S (2016) Hypoglycemic and antihyperglycemicactivity of aqueous extract of Justicia Schimperiana leavesin normal and streptozotocin-induced diabetic mice. IJPSR 7(2):110-113

23. Yadav S, Vats V, Dhunnoo Y (2002) Grover JK (2002) Hypoglycemic and antihyperglycemic activity of Murraya koenigii leaves in diabetic rats. J Ethnopharmacol 82:111-116
24. Dabla PK (2010) Renal function in diabetic nephropathy World. J Diabetes $1: 48-56$

25. Carmena R (2005) Type 2 diabetes, dyslipidemia, and vascular risk: Rationale and evidence for correcting the lipid imbalance. Am Heart J 150:859-870

26. Carmena R, Betteridge DJ (2004) Statins and diabetes. Semin Vasc Med 4:321-332

27. Solano MP (2006) Goldberg RB (2006) Lipid management in type 2 diabetes. Clin Diabetes 24:27-32

28. Papanas N, Maltezos E (2009) Oral antidiabetic agents: Antiatherosclerotic properties beyond glucose lowering? Curr Pharm Des 15:3179-3192

29. Molavi B, Rassouli N, Bagwe S, Rasouli N (2007) A review of thiazolidinediones and metformin in the treatment oftype 2 diabetes with focus on cardiovascular complications. Vasc Health Risk Manag 3:967-973

\section{Publisher's Note}

Springer Nature remains neutral with regard to jurisdictional claims in published maps and institutional affiliations.

\section{Submit your manuscript to a SpringerOpen ${ }^{\circ}$ journal and benefit from:}

- Convenient online submission

- Rigorous peer review

- Open access: articles freely available online

- High visibility within the field

- Retaining the copyright to your article

Submit your next manuscript at $\boldsymbol{\nabla}$ springeropen.com 